\title{
Temporomandibular disorders in adolescents with headache
}

\author{
Anna Sojka ${ }^{1, A-D}$, Marcin Żarowski ${ }^{2, A-D}$, Barbara Steinborn ${ }^{2, A, B}$, Wiesław Hedzelek ${ }^{1, A-C}$, \\ Beata Wiśniewska-Spychała ${ }^{3, B, C}$, Barbara Dorocka-Bobkowska, ${ }^{4, C, E, F}$ \\ ${ }^{1}$ Department of Prosthodontics, Poznan University of Medical Sciences, Poland \\ 2 Department of Developmental Neurology, Poznan University of Medical Sciences, Poland \\ ${ }^{3}$ Department of Dental Surgery, Poznan University of Medical Sciences, Poland \\ ${ }^{4}$ Department of Oral Pathology, Poznan University of Medical Sciences, Poland \\ A - research concept and design; $\mathrm{B}$ - collection and/or assembly of data; $\mathrm{C}$ - data analysis and interpretation; \\ $D$ - writing the article; $E$ - critical revision of the article; $F$ - final approval of the article
}

Address for correspondence

Barbara Dorocka-Bobkowska

E-mail:b.dorocka@gmail.com

\section{Funding sources}

None declared

Conflict of interest

None declared

Received on April 5, 2016

Reviewed on June 30, 2016

Accepted on September 1, 2016
DOI

10.17219/acem/64945

\section{Copyright}

Copyright by Author(s)

This is an article distributed under the terms of the

Creative Commons Attribution Non-Commercial License

(http://creativecommons.org/licenses/by-nc-nd/4.0/)

\begin{abstract}
Background. Headache is a common complaint in all age groups and is a frequent cause of medical consultations and hospitalization.

Objectives. The aim of this study was to evaluate the prevalence of bite and non-bite parafunctions as well as the signs and symptoms of temporomandibular disorder (TMD) in adolescents presenting with primary headaches.
\end{abstract}

Material and methods. Parents of adolescents presented with headaches to the Department of Developmental Neurology within a 12-month period were asked to complete a questionnaire developed by the authors of this study. Of the 1000 patients evaluated, 19 females and 21 males, aged 13 to 17 years, met the inclusion criterion - a confirmed clinical diagnosis of migraine or a tension headache according to the International Classification of Headache Disorders, $2^{\text {nd }}$ edition. The diagnostic algorithm of the study group consisted of a full medical history, an assessment of the occurrence of bite habits and a physical examination based on the Research Diagnostic Criteria for Temporomandibular Disorders (RDC/TMD).

Results. Bite and non-bite parafunctions were found in 36 of the study group patients. A significant difference ( $p=0.0003$ ) between the number of bite parafunctions and non-bite parafunctions was found in females but not in males. However, bite parafunctions were more frequent in boys compared to girls ( $p=0.01)$.

Conclusions. Our findings suggest that it may be useful for pediatricians and neurologists to include TMD dysfunctions as a part of a standard examination of adolescents presenting with persistent headaches.

Key words: temporomandibular disorders, headache, adolescents 


\section{Introduction}

Headaches are one of the most common complaints in all age groups and a frequent cause of medical consultation and hospitalization. ${ }^{1}$ They also have a significant impact on quality of life, with a detrimental effect on cognitive, emotional and social behavior. ${ }^{2}$ Chronic headaches, with an estimated prevalence of $10.0 \%$ in the pediatric population, contribute to school absence, decreased participation in extracurricular activities and poor school performance. ${ }^{3-7}$ Headaches can be broadly classified as primary or secondary. ${ }^{8}$ In the case of primary headaches, the problem lies in the pain itself - mainly migraine and tension-type pain. The diagnosis of primary headache is by means of the generally accepted clinical criteria developed by the International Headache Society, $2^{\text {nd }}$ edition (IHS-II). ${ }^{9}$ According to IHS-II, a headache can be attributed to temporomandibular disorders (TMD) when the coexistence of pain, mobility and acoustic symptoms of the temporomandibular joint are present. In the case of both headaches and TMD, pain can occur in the frontal, temporal, parietal and occipital regions. ${ }^{9}$ Population-based studies have previously examined the associations between TMD and psychological variables, pain conditions, and oral parafunctional habits. ${ }^{10,11}$ The international core tool used for TMD diagnosis is the Research Diagnostic Criteria for Temporomandibular Disorders (RDC/TMD) developed by Dworkin and LeResche and based on a biopsychosocial model. ${ }^{12}$ The RDC/TMD is derived from a consensus of leading researchers and clinicians and utilizes operationalized diagnostic criteria. ${ }^{12}$ The tool standardizes the evaluation and classification of patients, including young people with TMD, and assesses both physical disorder factors and psychosocial illness impact factors, axis I and axis II..$^{13} \mathrm{Axis}$ I is a set of diagnostic clinical procedures that provides data necessary for a physical diagnosis. Axis II assesses behavioral, psychosocial and quality-of-life aspects related to TMD pain diagnosis and treatment. ${ }^{12-15}$

In adolescents, a variety of TMD symptoms, such as pain in the pre-auricular area, tenderness during mandibular movements, joint crepitus or restricted mandibular movements, may be detected, although less frequently than in adult populations. ${ }^{16}$ The etiology of TMD is multifactorial in adolescents and may result from trauma, repetitive microtrauma from oral parafunctions (both bite and non-bite) and occlusal, systemic and psychological factors. ${ }^{10,11,17-20}$

It has been suggested that parafunctional activities may overload the dentition and masticatory system and may play an etiological role in the development of TMD. ${ }^{21}$ The detrimental effects of oral parafunctions will depend on their frequency, intensity and duration, as well as habits. Both masticatory and facial muscles respond to emotional states. ${ }^{17,22}$ The prevalence of TMD increases with age due to the escalating exposure of children and adolescents to stress at school, during exams and while adapting to adult life. ${ }^{21,23}$ Among the different oral parafunctional habits, teeth clenching and grinding, nail biting and gum chewing are most prevalent. ${ }^{24,25}$

Based on the results of Karibe et al., other pain conditions and parafunctional habits may exist that are related to TMD symptoms, even in a young population, and these factors should receive urgent attention. ${ }^{26}$ Oral bite and non-bite parafunctional habits involving repeated or sustained occlusal contact can be harmful to teeth and other components of the masticatory system and can affect the muscles and/or temporomandibular joint (TMJ). Hence, we investigated the prevalence of TMD symptoms in adolescents (12-17 years) with headaches, and assessed the occurrence of parafunctional habits and symptoms of TMD. In this study, we tested the hypothesis that TMD symptoms are associated with parafunctions in adolescents suffering from headaches.

\section{Material and methods}

Parents of all adolescents presenting with headaches in the Department of Developmental Neurology at Poznan University of Medical Sciences in Poland, from March 2013 to March 2014, were asked to complete a questionnaire survey developed by the authors of the study. Out of the 1000 patients evaluated in the Department, 40 children and adolescents aged 13-17 years met the inclusion criterion of the study - a confirmed clinical diagnosis of migraine or tension type headache according to the International Classification of Headache Disorders, $2^{\text {nd }}$ edition (ICHD-2). ${ }^{9}$ The mean age of the patients was $14.9 \pm 1.7$ years. During hospitalization, all the subjects in this group were examined by a certificated child neurologist and a full medical history was provided. Data from the questionnaire survey was also used to confirm the ICHD-2 criteria for migraine and tension type headache. The questionnaire study was approved by the Ethics Committee of the Poznan University of Medical Sciences, Poland.

\section{Questionnaire survey}

The diagnoses of all subjects in the investigated group were confirmed both by questionnaire and clinical assessment. The diagnostic algorithm used for the study group included a medical history, the occurrence of bite and non-bite parafunctions and a physical examination based on the RDC/TMD. ${ }^{12-15}$ The questionnaire survey focused on the characteristics of the headache, its frequency and the presence of additional symptoms. It also included questions about the history of head and neck injuries, mouth breathing, incorrect ingestion, and parafunctional habits. Parafunctional habits were categorized according to the following classification: bite habits (that involve the contact of opposing teeth), such as teeth grinding or/and habitual teeth clenching; non-bite habits (which do not involve the contact of opposing teeth) such as tongue, lip/cheek biting, biting or chewing on objects and/or nail biting. 


\section{Examination of TMD \\ - RDC/TMD questionnaire (axis II) and examination (axis I)}

All functional examinations of the stomatognathic system were performed by the same dentist as well as the evaluation of the occurrence of clinical TMD signs or symptoms. The clinical examination required about 10-15 min, whereas completing the questionnaire required up to 30-45 $\mathrm{min}$.

The axis II component of the RDC/TMD is a measure of depression and non-specific physical symptoms, typical pain intensity (characteristic pain intensity) and painrelated disability classification which are reliable and valid indicators with respect to the selected reference standards and for application to this patient population. Questions regarding sexual behavior were excluded. If a patient has experienced facial pain, or pain in the stomatognathic system or temples for the last month, the second part of the form was completed - the Chronic Pain Grade Protocol. ${ }^{12,13}$ This included pain insensitivity, disability due to pain, depression, fainting accidents, dizziness, heartache, and stomach or throat discomfort.

The physical examination was performed according to axis I of the RDC/TMD. The classification included 3 major groups: 1 . muscle disorders; 2 . disc displacements; 3. arthralgia, osteoarthritis, and osteoarthrosis of the TMJ. In order to diagnose a muscle-related TMD, pain must be present in the jaw, temples, face, pre-auricular area or inner ear at rest or during activities; tenderness/palpation must be present in at least 3 out of 20 palpation sites, with at least 1 tender site situated ipsilaterally to the complaint pain. The following areas were palpated bilaterally (with tenderness ranges of no pain, mild pain, moderate pain, and severe pain): the posterior/middle/anterior temporal muscle, superior/middle/inferior masseter muscle, posterior mandibular region, submandibular region, lateral/posterior pole of the temporomandibular joint, lateral pterygoid area and tendon of temporal muscle. Using the observed signs and symptoms, the RDC/TMD specifies diagnostic algorithms along with a classification system dividing TMD diagnoses into 3 main groups and 8 subgroups (Table 1). This classification system only applies to the most common TMD diagnoses. The examination included: measurement of the range of mandibular movements, assessment of pain in joints and muscles in motion, and palpation of clicks or crepitus during mandibular movements.

The presence of bite and non-bite parafunctions, occurrence of etiological factors of TMD, prevalence of TMD according to RDC/TMD, prevalence of headache in each TMD - elicited from patient history, and clinical examinations are presented in the tables as counts (in absolute numbers) while frequencies are expressed in percentages. A test for differences between 2 proportions was used to detect the differences between the occurrence of parafunctions and gender. To check the dependency between gender and TMD type, the $X^{2}$ test was used. The data obtained
Table 1. Categories of clinical conditions present in TMD, according to RDC/TMD axis

\begin{tabular}{|c|c|}
\hline Main groups & Diagnoses \\
\hline I - myofascial pain & $\begin{array}{c}\text { la }- \text { myofascial pain } \\
\text { lb - myofascial pain with limited opening }\end{array}$ \\
\hline II - disc displacements & $\begin{array}{c}\| \mathrm{a} \text { - disc displacement with reduction } \\
\text { Ilb - disc displacement without reduction, } \\
\text { with limited opening } \\
\text { Ilc-disc displacement without reduction, } \\
\text { without limited opening }\end{array}$ \\
\hline $\begin{array}{l}\text { III - arthralgia, } \\
\text { osteoarthritis, } \\
\text { osteoarthrosis }\end{array}$ & $\begin{array}{l}\text { IIla - arthralgia } \\
\text { IIIb - osteoarthritis of the temporo- } \\
\text { mandibular joint } \\
\text { IIlc - osteoarthrosis of the } \\
\text { temporomandibular joint }\end{array}$ \\
\hline
\end{tabular}

from the study was then analyzed using STATISTICA v. 10.0 (StatSoft Inc., Tulsa, USA). The level of significance was set at $\mathrm{p} \leq 0.05$.

\section{Results}

The study group consisted of 19 female (47.5\%) and 21 male (52.5\%) patients, aged 13 to 17 years. All participants had experienced episodes of headache for at least 3 months and this was the main reason for their admission to the department. A total of 12 participants (30.0\%) from the study group manifested migraine headaches according to ICHD-2 diagnostic criteria, while 28 participants (70.0\%) fulfilled the diagnostic criteria for tension type headaches.

In the examined group of 40 adolescents presenting with primary headaches, bite and non-bite parafunctions were found in 36 (90.0\%) patients. The study found no correlation between gender and the presence of parafunctional habits in general. There was a significant difference $(p=0.0003)$ between the number of bite (31.6\%) and non-bite parafunctions $(89.5 \%)$ in female patients, which was not observed in male patients $(\mathrm{p}=0.73)$. Boys $(71.4 \%)$ presented more frequently with bite parafunctions compared to girls (31.6.0\%; $\mathrm{p}=0.01$ ) (Table 2). In patients with a history of head trauma, malocclusion, abnormal swallowing or mouth breathing, the number of bite and non-bite parafunctional habits was high, ranging from $81.8 \%$ to $100 \%$ (Table 3).

\section{RDC/TMD examination (axis I)}

Using the axis I RDC/TMD diagnostic criteria, it was found that among 40 adolescents presenting with headaches, 16 patients (40.0\%) suffered from muscle disorders (Ia), 13 patients $(32.5 \%)$ had disc displacement with reduction (IIa) and 11 patients (27.5\%) showed no dysfunctions. Bite and non-bite parafunctions were present in 100\% of cases with muscle disorders (Ia), 100\% of cases with disc displacement with reduction (IIa) and in 63.6\% of patients with no symptoms of TMD (Table 4). Analysis of the 16 patients with muscle disorder (Ia) showed that the 
Table 2. Presence of bite and non-bite parafunctions in the group of adolescents presenting with headache

\begin{tabular}{|c|c|c|c|c|c|}
\hline \multirow{3}{*}{$\begin{array}{l}\text { Study group } \\
\qquad(\%)\end{array}$} & \multicolumn{4}{|c|}{ Parafunctions } & \multirow{3}{*}{$\begin{array}{l}p \text {-value } \\
p=0.0003\end{array}$} \\
\hline & \multicolumn{2}{|c|}{$\begin{array}{l}\text { bite parafunctions } \\
n(\%)\end{array}$} & \multicolumn{2}{|c|}{$\begin{array}{c}\text { non-bite } \\
\text { parafunctions } \\
\mathrm{n}(\%)\end{array}$} & \\
\hline & $6(31.6)$ & \multirow{2}{*}{$p=0.01$} & $17(89.5)$ & \multirow{2}{*}{ ns } & \\
\hline Boys 21 (52.5) & 15 (71.4) & & $16(76.2)$ & & ns \\
\hline Total 40 (100) & \multicolumn{2}{|l|}{$21(52.5)$} & \multicolumn{2}{|l|}{$33(82.5)$} & - \\
\hline
\end{tabular}

There was a significant difference $(p=0.0003)$ between the number of bite (31.6\%) and non-bite parafunctions (89.5\%) in girls, which was not observed in the case of boys ( $p=0.72$ ). The study revealed no statistically significant differences (ns) between girls and boys in the case of non-bite parafunctions $(p=0.3)$. However, bite parafunctions $(p=0.01)$ presented more frequently in boys.

Table 3. Occurrence of parafunctions depending on TMD etiological factors in adolescents

\begin{tabular}{|l|c|c|}
\hline \multicolumn{1}{|c|}{ Etiological factors of TMD } & $\begin{array}{l}\mathrm{n}=40 \\
(\mathbf{1 0 0 \% )}\end{array}$ & $\begin{array}{c}\text { Bite and non-bite } \\
\text { parafunctions n (\%) }\end{array}$ \\
\hline Malocclusion & $18(45.0)$ & $18(100)$ \\
\hline Head injuries & $11(27.5)$ & $9(81.8)$ \\
\hline Breathing through the mouth & $11(27.5)$ & $10(90.9)$ \\
\hline Incorrect ingestion & $10(25.0)$ & $9(90.0)$ \\
\hline
\end{tabular}

pain was mainly located in the frontal (50.0\%) and temporal region (43.8\%). Among the 13 patients manifesting disc displacement with reduction (IIa), 38.5\% experienced pain in the temporal, parietal and occipital region and $30.8 \%$ in the frontal region. Among the 11 patients showing no symptoms from TMJ, $90.9 \%$ of cases experienced headache in the frontal region (Table 5).

\section{Chronic Pain Grade classification and depression RDC/TMD questionnaire survey (axis II)}

The prevalence of chronic pain located in the facial area (Chronic Pain Grade) according to RDC/TMD axis II is presented in Fig. 1. To facilitate the interpretation of data, the 4 grade scale of chronic pain used in RDC/TMD questionnaire was simplified to: 0 - absence of pain and 1 - presence of pain. In 16 subjects presenting with muscle disorder (Ia) chronic pain was diagnosed in $62.5 \%$. Among 13 patients presenting with disc displacement with reduction (IIa) chronic pain was present in $69.2 \%$. Among

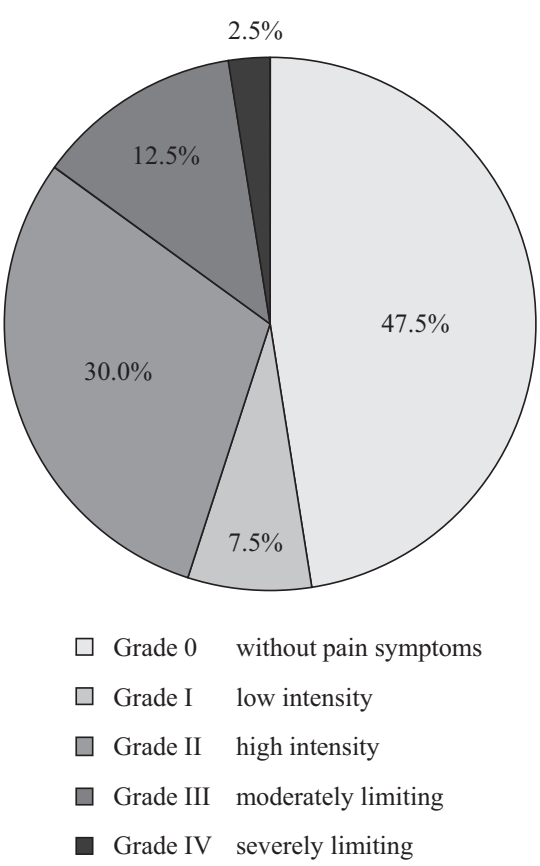

Fig. 1. Classification of the severity of chronic pain according to RDC/TMD axis II (headache groups)

Table 4. Prevalence of TMD in the group of adolescents suffering from headache according to RDC

\begin{tabular}{|l|c|c|c|c|}
\multicolumn{1}{|c|}{ TMD diagnoses (axis I) } & $\begin{array}{c}\text { Total } \\
n=40(\%)\end{array}$ & $\begin{array}{c}\text { Girls } \\
n=19(\%)\end{array}$ & $\begin{array}{c}\text { Boys and non-bite parafunctions } \\
n=21(\%) \\
\text { of every TMD } \\
n=40(\%)\end{array}$ \\
\hline la - myofascial pain & $16(40.0)$ & $8(42.1)$ & $8(38.1)$ & $16(100)$ \\
\hline Ila - disc displacement with reduction & $13(32.5)$ & $7(36.8)$ & $6(28.6)$ & $7(33.3)$ \\
\hline 0 - no disorder & $11(27.5)$ & $4(21.1)$ & $21(100)$ & $7(63.6)$ \\
\hline Total & $40(100)$ & $19(100)$ & $36(90.0)$ \\
\hline
\end{tabular}

Table 5. Prevalence of headache in each TMJ disorder according to RDC/TMD axis I diagnostic criteria

\begin{tabular}{|c|c|c|c|c|c|}
\hline TMD diagnoses (axis I) & $\begin{array}{l}\text { Frontal region } \\
\mathrm{n}(\%)\end{array}$ & $\begin{array}{c}\text { Parietal region } \\
\mathrm{n}(\%)\end{array}$ & $\begin{array}{c}\text { Temporal region } \\
\mathrm{n}(\%)\end{array}$ & $\begin{array}{c}\text { Occipital region } \\
\mathrm{n}(\%)\end{array}$ & $\begin{array}{c}\text { Frontal + temporal + parietal } \\
+ \text { occipital region } \\
n(\%)\end{array}$ \\
\hline la - myofascial pain $(n=16)$ & $8(50.0)$ & $1(6.3)$ & $7(43.8)$ & $1(6.3)$ & $2(12.5)$ \\
\hline $\begin{array}{l}\text { Ila }- \text { disc displacement with } \\
\text { reduction }(n=13)\end{array}$ & $4(30.8)$ & $5(38.5)$ & $5(38.5)$ & $5(38.5)$ & $1(7.7)$ \\
\hline 0 - no disorder $(n=11)$ & $10(90.9)$ & 0 & 0 & $1(9.1)$ & 0 \\
\hline
\end{tabular}


Table 6. Prevalence (\%) of depression and non-specific physical symptoms with a pain component and non-specific physical symptoms without a pain component in RDC/TMD diagnoses, axis I (headache groups)

\begin{tabular}{|l|c|c|c|}
\multicolumn{1}{|c|}{ TMD diagnoses (axis I) } & $\begin{array}{c}\text { Depression } \\
n(\%)\end{array}$ & $\begin{array}{c}\text { Non-specific physical symptoms, } \\
\text { with pain items } \\
n(\%)\end{array}$ & $\begin{array}{c}\text { Non-specific physical symptoms, } \\
\text { without pain items } \\
n(\%)\end{array}$ \\
\hline la - myofascial pain $(n=16)$ & $1(6.3)$ & $3(18.8)$ & $1(6.3)$ \\
\hline Ila - disc displacement with reduction $(n=13)$ & $1(7.7)$ & $4(30.8)$ & $1(7.7)$ \\
\hline
\end{tabular}

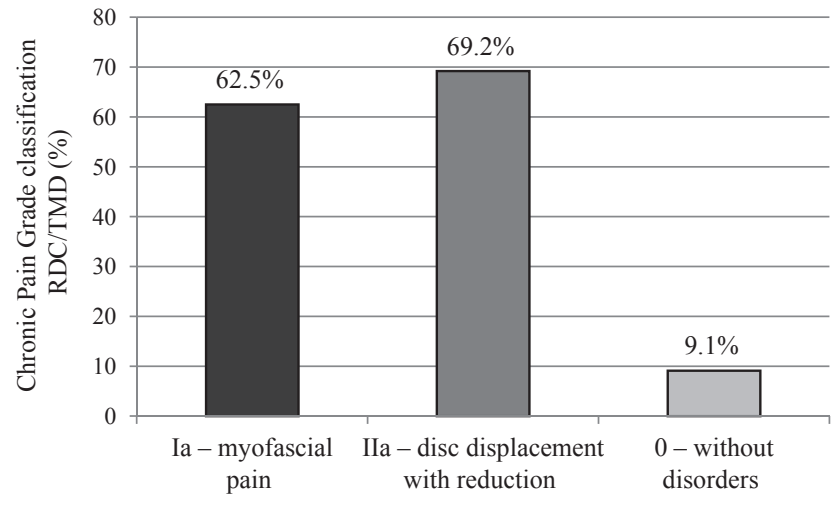

Fig. 2. Prevalence of chronic pain (according to Chronic Pain Grade) RDC/TMD axis II in TMD diagnoses (axis I) (headache groups)

patients showing no symptoms from TMJ chronic pain was experienced by only $9.1 \%$ (Fig. 2).

The depression and somatization symptoms grade scale, according to the RDC/TMD diagnostic criteria, was also simplified as: 0 - absence of pain and 1 - presence of pain. Depression was diagnosed in 1 patient in the Ia group and 1 patient in the Ila group. Non-specific physical symptoms were present in 3 cases in the Ia and 4 cases in the IIa group (Table 6). Subjects without TMD did not show any depression or non-specific physical symptoms.

\section{Discussion}

Recent studies of young (preschool to maturity) outpatients and inpatients have revealed that the number of headache cases has increased over recent years. ${ }^{10,27,28}$ An accurate analysis of headache characteristics is crucial for a proper differential diagnosis. ${ }^{29,30}$ Long term stress provokes emotional anxiety and increases muscle hyperactivity and tension. ${ }^{9,10,31}$ Chronic muscle tension can lead to headaches located in the temporal, frontal, parietal or occipital region. Liljeström et al. observed a correlation between TMD and headache in a group of adolescents with primary headache and concluded that TMD should always be considered when headaches are associated with ear pain, difficulty in opening the mouth and fatigue or stiffness of the jaw. ${ }^{32}$ Bertoli et al. evaluated the signs and symptoms of TMD in 50 children, aged 4-18 years, who had headaches. ${ }^{18}$ They found a higher prevalence of signs and symptoms of TMD in patients with headaches compared to the control group.

Adolescents with TMD have reported significantly higher levels of stress and psychosocial problems. ${ }^{33}$ Other researchers have demonstrated a correlation between headache and stress level, parafunctional habits, pops and clicks in the TMJ, and pain during mandibular movement. ${ }^{21,26,34}$ Subjects may be unaware of diurnal clenching and nocturnal tooth grinding while sleeping. ${ }^{11,35}$ Considering the high frequency of parafunctions and TMD in children and adolescents, epidemiological research into the morphological and functional causes would be of great benefit. ${ }^{11,16,27,36,37}$

In our study, in the group of adolescents presenting with primary headache, $36(90.0 \%)$ of the subjects were found to have bite and non-bite parafunctions. Bite parafunctional habits were present in $52.5 \%$ of cases while $82.5 \%$ of subjects revealed non-bite habits. It was demonstrated that occlusal parafunctions appeared more frequently in male patients. There was also a significant difference between the number of bite parafunctions (31.6\%) and nonbite parafunctions $(89.5 \%)$ in girls, but not in boys. No significant difference was noted in non-bite parafunctional habits between female and male patients.

All patients with a diagnosed muscle disorder or disc displacement with reduction displayed bite and non-bite parafunctional habits. The results are consistent with that of Glaros et al. ${ }^{38}$ Farsi et al. in their population studies of school children did not find any differences in the number of TMD symptoms between genders, but revealed a more frequent occurrence of non-bite parafunctions compared to bite parafunctions. ${ }^{25}$ Nail biting was the most common non-bite oral parafunction $(27.7 \%)$ while bruxism proved to be the least common parafunction (8.4\%).

Among the etiological factors, traumas, including head traumas, often occur in children and adolescents, and may be a source of headaches as well as TMJ disorders. ${ }^{39} \mathrm{Katz}-$ berg et al. showed that traumas are the cause of $26.0 \%$ of TMD in children and adolescents. ${ }^{40}$ TMJ injury can occur due to impact (car accidents, contact sports), biting on hard objects or opening the mouth too wide. In the group of 40 subjects, $27.5 \%$ of participants had a history of head trauma with $81.8 \%$ exhibiting bite and non-bite parafunctions. Other etiological factors of these dysfunctions included malocclusion, abnormal swallowing or mouth breathing. Such activities in combination with 
parafunctional habits may accelerate the development of TMJ disorders.

Carlsson et al. reported malocclusion in 35.0-95.0\% of randomly selected 7-, 11- and 15-year-old subjects. ${ }^{41}$ Our results demonstrate the presence of malocclusion in $45 \%$ of cases, mouth breathing in $27.5 \%$ of cases, abnormal swallowing in $25 \%$ of cases, and parafunctions in $81.8-100 \%$ of cases. Over the past several decades, the age of patients presenting with TMD has been gradually decreasing. ${ }^{41}$ In individuals from 7 to 11 years old, the number of disorders increased rapidly from $30.0 \%$ to $60.0 \%$; while the age group 12 to 14 showed no increase until the age of 19 , when the disorders increased to $80.0 \%$. Studies of adult subjects have revealed that TMD symptoms are twice as frequent in females than in males. ${ }^{42,43}$ However, there was no significant difference in TMD incidence between males and females in the age group studied.

Analysis of the location of pain was also performed in 16 patients with muscle disorders, where (Ia) pain affected the forehead (50.0\%) and temples (43.8\%). Of the 13 subjects presenting with disc displacement with reduction (IIa), the pain was located in the temporal, parietal and occipital region (38.5\%), and frontal region (30.8\%). Among the 11 patients without TMD, $90.9 \%$ of cases involved the frontal region. Ballegaard et al. examined adult patients presenting with headaches and discovered a high $(83.0 \%)$ percentage of disabilities caused by chronic pain of the face and TMJ..$^{44}$ In contrast, our findings demonstrate that chronic pain (Chronic Pain Grade) in children occurs to a lesser extent (52.5\%). Among the subjects presenting with muscle disorders (Ia), $62.5 \%$ of patients suffered from pain. However, $69.2 \%$ of patients presenting with disc displacement with reduction (IIa) experienced pain. Some children with TMD symptoms did not develop any facial pain.

Currently, the significance of psychophysical factors as a cause of diseases and TMJ disorders is being emphasized. List et al. revealed that, in adolescents with TMD, psychosocial factors such as increased levels of stress, somatic complaints and emotional problems seem to play a prominent role. ${ }^{33}$ The chief factors include: stress, nervousness, depression, and anxiety. The depression scale SCL-90 elaborated by Derogatis et al. has been included in the RDC/TMD diagnostic criteria by Dworkin et al. ${ }^{12,45}$ Mental state assessment by Ballegaarda et al. revealed that $54.5 \%$ of patients with headache were affected by moderate to severe depression. ${ }^{44}$ Our findings revealed that children and adolescents suffered from depression and nonspecific physical syndromes to a lesser degree: depression in $6.3-7.7 \%$ of cases and nonspecific physical syndromes in $18.8-30.8 \%$ of cases. Patients without any TMD symptoms showed no depression or nonspecific physical syndromes.

\section{Conclusions}

1. On the basis of patient history and clinical examination of adolescents presenting with primary headache, a high incidence of TMD symptoms, bite and non-bite parafunctional habits was found.

2. This paper underscores the need for a multilevel diagnostic and therapeutic approach, the importance of a rigorous examination of the stomatognathic system and the identification of a destructive influence of parafunctional habits in adolescents suffering from headache.

3. RDC/TMD classification is a helpful tool for diagnosing TMD in children and youth presenting with primary headache.

\section{References}

1. Ravishankar R. The art of history-taking in a headache patient. Ann Indian Acad Neurol. 2012;15:7-14.

2. Özge A, Termine C, Antonaci F. Overview of diagnosis and management of pediatric headache. Part I: Diagnosis. J Head Pain. 2011; 12:13-23.

3. Abu-Arefeh I, Russell G. Prevalence of headache and migraine in schoolchildren. BMJ. 1994;309:765-769.

4. De Luca GC, Bartleson JD. When and how to investigate the patient with headache. Semin Neurol. 2010;30:131-144.

5. Fallone G, Owens JA, Deane J. Sleepiness in children and adolescents: Clinical implications. Sleep Med. 2002;6:287-306.

6. Luc ME, Gupta A, Birnberg JM, Reddick D, Kohrman MH. Characterization of symptoms of sleep disorders in children with headache. Pediatr Neurol. 2006;34:7-12.

7. Neveus T, Cnattingius S, Olsson U, Hetta J. Sleep habits and sleep problems among a community sample of schoolchildren. Acta Pediatr. 2001;90:1450-1455.

8. Bugdayci R, Ozge A, Sasmaz T, et al. Prevalence and factors affecting headache in Turkish school children. Pediatr Int. 2005;47:316-322.

9. International Headache Society: The International Classification of Headache Disorders $2^{\text {nd }}$ edition. Cephalalgia. 2004;24(Suppl 1):1-160.

10. Minghelli B, Cardoso I, Porfírio M, et al. Prevalence of temporomandibular disorder in children and adolescents from public schools in southern Portugal. N Am J Med Sci. 2014;6:126-132.

11. Carra MC, Huynh N, Morton P, et al. Prevalence and risk factors of sleep bruxism and wake-time tooth clenching in a 7- to 17-yr-old population. Eur J Oral Sci. 2011;119:386-394.

12. Dworkin SF, LeResche L. Research diagnostic criteria for temporomandibular disorders: Review, criteria, examinations and specifications, critique. J Craniomand Dis. 1992;6:301-355.

13. Pereira L, Pereira-Cenci T, Pereira SM, et al. Psychological factors and the incidence of temporomandibular disorders in early adolescence. Braz Oral Res. 2009;23:155-160.

14. Franco-Micheloni AL, Fernandes G, de Godoi Gonçalves DA, Camparis CM. Temporomandibular disorders in a young adolescent Brazilian population: Epidemiologic characterization and associated factors. J Oral Facial Pain Headache. 2015;29:242-249.

15. Pizolato RA, de Freitas Fernandes FS, Duarte Gavião MB. Anxiety/ depression and orofacial myofacial disorders as factors associated with TMD in children. Braz Oral Res. 2013;27:155-162.

16. Howard JA. Temporomandibular joint disorders in children, pediatric dentistry. Dent Clin North Am. 2013;57:99-127.

17. Nilson IM, List T, Drangsholt M. Prevalence of temporomandibular pain and subsequent dental treatment in Swedish adolescents. J Orofac Pain. 2005;19:144-150.

18. Bertoli FM, Antoniuk SA, Bruck I, Xavier GR, Rodrigues DC, Losso EM. Evaluation of the signs and symptoms of temporomandibular disorders in children with headaches. Arq Neuropsiquiatr. 2007;65:251-255.

19. Wahlund K. Temporomandibular disorders in adolescents: Epidemiological and methodological studies and a randomized controlled trial. Swed Dent J. 2003;164:264. 
20. Vanderas AP, Papagiannoulis L. Multifactorial analysis of the aetiology of craniomandibular dysfunction in children. Int J Pediatr Dent. 2002;12:336-346.

21. Winocur E, Littner D, Adams I, Gavish A. Oral habits and their association with signs and symptoms of temporomandibular disorders in adolescents: A gender comparison. Oral Surg, Oral Med, Oral Pathol, Oral Radiol Endod. 2006;102:482-487.

22. Pillemer FG, Masek BJ, Kaban LB. Temporomandibular joint dysfunction and facial pain in children: An approach to diagnosis and treatment. Pediatrics. 1987;80:565-570.

23. Köhler AA, Helkimo AN, Magnusson T, Hugoson A. Prevalence of symptoms and signs indicative of temporomandibular disorders in children and adolescents: A cross-sectional epidemiological investigation covering two decades. Eur Arch Pediatr Dent. 2009;10: 16-25.

24. Feteih RM. Signs and symptoms of temporomandibular disorders and oral parafunctions in urban Saudi Arabian adolescents: A research report. Head Face Med. 2006;2:1-7.

25. Farsi NM. Symptoms and signs of temporomandibular disorders and oral parafunctions among Saudi children. J Oral Rehabil. 2003;30: 1200-1208.

26. Karibe H, Shimazu K, Okamoto A, Kawakami T, Kato Y, Warita-Nao S. Prevalence and association of self-reported anxiety, pain, and oral parafunctional habits with temporomandibular disorders in Japanese children and adolescents: A cross-sectional survey. BMC Oral Health. 2015;21:15-18.

27. Branco LP, Santis TO, Alfaya TA, Godoy CHL, Fragoso YD, Bussadori SK. Association between headache and temporomandibular joint disorders in children and adolescents. J Oral Sci. 2013;55:39-43.

28. Antonaci F, Voiticovschi-losob C, Di Stefano AL, Galli F, Ozge A, Balottin $U$. The evolution of headache from childhood to adulthood: A review of the literature. J Headache Pain. 2014;15:15-19.

29. Hershey AD. Recent developments in pediatric headache. Curr Opin Neurol. 2010;23:249-253.

30. Gladstein J, Rothner AD. Chronic daily headache in children and adolescents. Sem Pediatr Neurol. 2010;17:88-92.

31. Lundeen TF, Sturdevant J, George JM. Stress as a factor in muscle and temporomandibular joint pain. J Oral Rehabil. 1987;14:1365-2842.

32. Liljeström M, Le Bell Y, Anttila P, et al. Headache children with temporomandibular disorders have several types of pain and other symptoms. Cephalalgia. 2005;25:54-60.
33. List $\mathrm{T}$, Wahlund $\mathrm{K}$, Larsson $\mathrm{B}$. Psychosocial functioning and dental factors in adolescents with temporomandibular disorders: A case-control study. J Orofacial Pain. 2001;15:218-227.

34. Leistad RB, Sand T, Westgaard RH, Nilsen KB, Stovner LJ. Stress-induced pain and muscle activity in patients with migraine and tension-type headache. Cephalalgia. 2006;26:64-73.

35. Michelotti A, Cioffi I, Festa P, Scala G, Farella M. Oral parafunctions as risk factors for diagnostic TMD subgroups. J Oral Rehabil. 2010;37: 157-162.

36. Motta LJ, Guedes CC, De Santis TO, Fernandes KPS, Mesquita-Ferrari RA, Bussadori SK. Association between parafunctional habits and signs and symptoms of temporomandibular dysfunction among adolescents. Oral Health Prev Dent. 2013;11:3-7.

37. Winocur E. Oral habits among adolescent girls and their association with symptoms of temporomandibular disorders. J Oral Rehabil. 2001;28:624-629.

38. Glaros AG, Urban D, Locke J. Headache and temporomandibular disorders: Evidence for diagnostic and behavioural overlap. Cephalalgia. 2007;27:542-549.

39. Emodi-Perlman A, Eli I, Friedman-Rubin P, Goldsmith C, Reiter S, Winocur E. Bruxism, oral parafunctions, anamnestic and clinical findings of temporomandibular disorders in children. J Oral Rehabil. 2012;39:126-135.

40. Katzberg R, Tallents R, Hayakawa K, Miller T, Goske M, Wood B. Internal derangements of the temporomandibular joint: Findings in the pediatric age group. Radiology. 1998;154:125-127.

41. Carlsson G, Egermark I, Magnusson T. Predictors of signs and symptoms of temporomandibular disorders: A 20-year follow-up study from childhood to adulthood. Acta Odontol Scand. 2002;60:180-181.

42. LeResche L. Epidemiology of temporomandibular disorders: Implications for the investigation of etiologic factors. Crit Rev Oral Biol Med. 1997:8:291-305.

43. Dao TT, LeResche L. Gender differences in pain. J Orofac Pain. 2000; 14:169-184.

44. Ballegaard V, Thede-Schmidt-Hansen P, Svensson P, Jensen R. Are headache and temporomandibular disorders related? A blinded study. Cephalalgia. 2008;28:832-841.

45. Derogatis LR, Melisaratos N. The brief symptom inventory: An introductory report. Psychol Med. 1983;13:595-605. 